\section{Responsible innovation}

\section{In brief}

- Responsible Research and Innovation (RRI) is at the top of the European research policy agenda.

- Research, technology and innovation (RTI) actors should make significant contributions to solving the major societal challenges. In addition to economic benefits, the societal benefits of technologies should also be considered.

- $\quad$ For RRI to be successful, decision-makers must realign the framework for RTI policies. The EU has developed a number of proposals for this. However, these should be refined and adapted to national conditions.

\section{What is it about?}

There is a lot of untapped potential in research and innovation to find solutions to the most pressing problems of our time. These include climate change and an ageing society as well as food security. Against this background, the buzzword "Responsible Research and Innovation" (RRI) keeps being mentioned more frequently. RRI calls for all actors in research and innovation processes to assume joint responsibility for contributing to meeting these challenges.

RRI is a model that is oriented towards long-term goals. In essence, it is about actively promoting and shaping promising innovations. At the same time, the associated social, ethical and environmental impacts are to be estimated in advance. Unwanted side effects can thus be minimised in advance and not just regulated retrospectively with a lot of effort. RRI affects the entire innovation process, not just individual technologies. The innovation process should not be based solely on market successes, but consider many more fundamental values, and place special emphasis on societal benefit.
All persons involved in research and innovation take responsibility by identifying possible consequences of their work at an early stage. The associated options for action can then be systematically evaluated according to the extent to which they correspond to social needs and values. The fundamental questions are as follows: What kind of innovation do we want? What is it supposed to achieve for us as a society? What kind of research should be funded? RRI thus emphasises the importance of the public for innovation processes. Societal desirability and acceptance, in addition to economic benefits, will thus become central drivers of RTI.

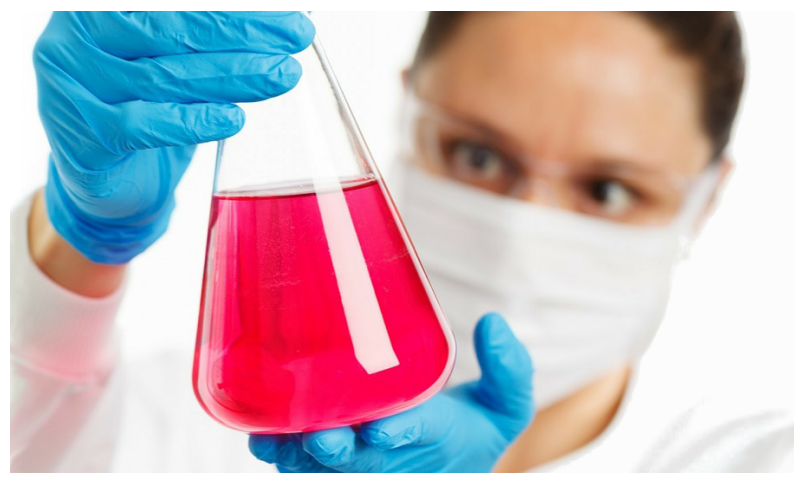

For whom is research done?

The fact that technologies are to be developed responsibly is nothing new. Various branches of research have long been concerned with this goal: participation, forward-looking governance, open innovation, socio-technical integration, and last but not least, technology assessment. What is new about $\mathrm{RRI}$ is that it builds on these different approaches and connects them in a new way. The goal: a profound change in research policy and the innovation system. The concept is already a fundamental cross-cutting theme for EU research funding.

However, for RRI to really make an impact, lots more still needs to be done. At present, politicians and researchers are primarily concerned with the future of RRI. There is a lack of a broader discourse that systematically includes industry and non-governmental organisations. From an Austrian point of view, the adaptation of the European draft to national circumstances is particularly missing. It is precisely here that technology assessment can make a significant contribution to the formulation and implementation of RRI.

Technology assessment draws on many years of practical experience in assessing the consequences of technical innovations. For example, foresight and participation methods are applied and continuously refined. 


\section{Implementation - but how?}

RRI can create a new framework for research and innovation in Europe. In the future, innovative products and services will increasingly orientate themselves towards fundamental European values and contribute specifically to finding solutions to the great societal challenges of the $21^{\text {st }}$ century. The following key criteria, amongst others, have been proposed at EU level for the implementation of RRI:

Participation. As many actors as possible should participate in research and innovation processes at an early stage: researchers, industry, policy makers, civil society organisations, and individual citizens.

Equality. Research institutions must offer equal opportunities for men and women. Gender aspects should be given greater consideration in research and development.

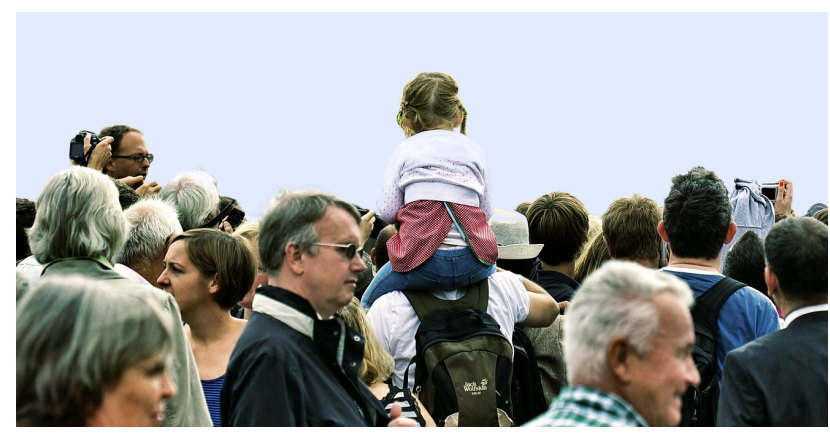

Changing times: Economic success alone is not enough. Research and innovation must demonstrate social responsibility

Scientific education. Conditions must be created so that people in research and development can take responsibility for socially important topics.

Ethics. RRI explicitly refers to values and fundamental rights shared throughout Europe. Ethical standards are understood as an incentive and standard to produce relevant and acceptable research results, products, and services.

Open Access. Transparency and free access to scientific results from publicly funded research should stimulate and support innovation.

The criteria proposed by the EU Commission should contribute to the implementation of RRI. However, not everything that can be related to them is already a contribution to RRI. It would also be a mistake wanting to define basic research as a specific societal benefit from the outset - ethical standards, on the other hand, also apply to basic research.

\section{What to do?}

In Austrian research and innovation policy, RRI has played only a minor role so far. However, the new approach has a high priority in the European research area. Therefore, a more in-depth discussion of RRI at national level is essential. There is a particular need for action in three areas:

- Research needs. RRI basically aims at a completely different innovation system with new rules, objectives and institutional arrangements. Therefore, fundamental studies should comprehensively analyse the potential impact of RRI on the existing national innovation system. In particular, an evaluation of the Austrian research funding landscape with regard to RRI would be useful.

- Development of mission statements. Ongoing refinement of $\mathrm{RRI}$ is essential. Discussions on the content, necessary instruments and methods as well as the political feasibility are urgently needed. Overall, it is a question of a productive discussion of the mission statement and the development of specific Austrian priorities and positions on RRI.

- Framework for constructive discourse. In order to further develop RRI, representatives of politics, research funding, science, industry, and civil society must work together. Politicians should actively promote exchange and create appropriate framework conditions for constructive dialogue.

\section{Further reading}

European Commission (2013) Options for Strengthening Responsible Research and Innovation, EUR25766 EN, ec.europa.eu/research/sciencesociety/document library/pdf 06/options-forstrengthening en.pdf

\section{Contact}

\section{Michael Nentwich}

Email: tamail@oeaw.ac.at

Phone: +43(1)51581-6582

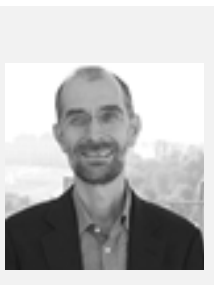

IMPRINT: Owner: Austrian Academy of Sciences; Legal person under public law (BGBI. 569/1921 i.d.F. BGBI. I 130/2003); Dr. Ignaz Seipel-Platz 2, A-1010 Vienna; Editor: Institute of Technology Assessment (ITA); Apostelgasse 23, A-1030 Vienna; www.oeaw.ac.at/en/ita/. | Frequency: The ITA Dossiers are published irregularly and publish the research results of the ITA. The ITA Dossiers are published in print in small numbers only and are made available open access to the public via the Internet portal "epub.oeaw": epub.oeaw.ac.at/ita/ita-dossiers | ISSN: 2306-1960 | This work is licensed under a Creative Commons Attribution 4.0 International License: creativecommons.org/licenses/by/4.0/ | ITA Dossier no. 013, November 2014 | epub.oeaw.ac.at/ita/ita-dossiers/ita-@) (i) dossier013en.pdf | 